\title{
THYROID CANCER IN A PATIENT WITH NEUROFIBROMATOSIS TYPE 1 - VON RECKLINGHAUSEN DISEASE
}

I Karaitianos, P Athanassiou, C Tsomidou, I Kostoglou-Athanassiou

Department of Surgery, St. Savvas Hospital, Athens, Greece

Department of Rheumatology, St. Paul's Hospital, Thessaloniki, Greece

Department of Medicine, Hippocrates Hospital, Piraeus, Greece

Department of Endocrinology, Red Cross Hospital, Athens, Greece

\section{OBJECTIVES}

Neurofibromatosis type 1 or von Recklinghausen disease is a systemic hereditary disease characterized by disorders regarding the skin, neural and skeletal systems. Osteoporosis is one of the skeletal manifestations of neurofibromatosis type 1 , being associated with increased fracture risk. Neurofibromatosis type 1 is associated with a propensity for the development of cancer, breast cancer in particular being associated with neurofibromatosis type 1 .

The aim was to present the case of a patient with neurofibromatosis type 1 who developed breast and thyroid cancer and was diagnosed with osteoporosis.

\section{CONCLUSIONS}

Neurofibromatosis type 1 is a systemic hereditary disease characterized by a tendency for the development of cancer. Recently, osteoporosis has been described as one of the features of the disease. The case of a patient has been described with neurofibromatosis type 1 and osteoporosis who improved after treatment with risedronate (Benlidayi et al, 2015). The patient described herein was also given bisphosphonates with a good therapeutic response.

\section{METHODS}

A female patient, aged 47 , with neurofibromatosis type 1 developed breast cancer at the age of 45 and had surgery and radiotherapy. The patient had a mother with neurofibromatosis type 1 , who had breast cancer and had died from metastatic generalized breast cancer. A year later the patient presented with a nodule in the thyroid gland. Fine needle aspiration biopsy was performed and revealed the presence of papillary thyroid cancer.

\section{RESULTS}

Near total thyroidectomy was performed and histology was positive for a papillary thyroid cancer. The patient complained for diffuse musculoskeletal pain, $25(\mathrm{OH}) \mathrm{D}_{3}$ levels and bone mineral density were measured. $25(\mathrm{OH}) \mathrm{D}_{3}$ levels were $20 \mathrm{ng} / \mathrm{ml}$, T score was -2.9 . Ibandronate was administered at a dose of $150 \mathrm{mg}$ once monthly along with calcium and vitamin D orally. A year later bone mineral density was measured, T score being -2.7 , compatible with improvement in bone mineral density.

\section{References}

Doulias T, Papaziogas B, Rosser JH, Koutelidakis I. Thyroid neurofibroma in a female patient with neurofibromatosis type I: report of a case. BMJ Case Rep 2013.

Ercolino T, Lai R, Giachè V, Melchionda S, Carella M, Delitala A, Mannelli M, Fanciulli G. Patient affected by neurofibromatosis type 1 and thyroid C-cell hyperplasia harboring pathogenic germ-line mutations in both NF1 and RET genes. Gene 2014; 536:332-5. 